\title{
New Aspects of Neurotransmitter Release and Exocytosis: Dynamic and Differential Regulation of Synapsin I Phosphorylation by Acute Neuronal Excitation In Vivo
}

\author{
Yoko Yamagata* \\ Laboratory of Neurochemistry and Department of Information Physiology, National Institute for Physiological Sciences, \\ and The Graduate University for Advanced Studies (SOKENDAI), Myodaiji, Okazaki 444-8585, Japan
}

Received May 2, 2003; Accepted June 27, 2003

\begin{abstract}
Synapsin I is a synaptic vesicle-associated protein that is phosphorylated at multiple sites by various protein kinases. It has been proposed to play an important role in the regulation of neurotransmitter release and the organization of cytoskeletal architecture in the presynaptic terminal. In the present minireview, I describe the dynamic changes in synapsin I phosphorylation induced by acute neuronal excitation in vivo, and discuss its regulation by protein kinases and phosphatases and its functional significance in vivo. When acute neuronal excitation was induced by electroconvulsive treatment (ECT) in rats, phosphorylation of synapsin I at multiple sites was decreased during brief seizure activity in hippocampal and parieto-cortical homogenates. After termination of the seizure activity, phosphorylation at mitogen-activated protein kinase-dependent sites was increased dramatically. Phosphorylation at a $\mathrm{Ca}^{2+} /$ calmodulin-dependent protein kinase II-dependent site was also increased moderately afterwards. The dynamic and differential changes in synapsin I phosphorylation induced by acute neuronal excitation may be involved in plastic changes induced by ECT and may have some role in its effectiveness for the treatment of psychiatric diseases in humans.
\end{abstract}

Keywords: synapsin I, phosphorylation, dephosphorylation, mitogen-activated protein kinase, $\mathrm{Ca}^{2+} /$ calmodulin-dependent protein kinase II

\section{Introduction}

Synapsin I is a representative synaptic vesicle-associated phosphoprotein and localizes exclusively in the presynaptic terminal. Its phosphorylation state controls its association to synaptic vesicles and actin filaments and has been considered to play an important role in the regulation of neurotransmitter release and presynaptic actin network organization. Synapsin I is phosphorylated at multiple sites by various protein kinases (Fig. 1). Cyclic AMP-dependent protein kinase (PKA) and $\mathrm{Ca}^{2+}$ /calmodulin-dependent protein kinase I (CaMKI) phosphorylate Ser-9 (site 1); $\mathrm{Ca}^{2+} /$ calmodulin-dependent protein kinase II (CaMKII) phosphorylates Ser-566 and Ser-603 (sites 2 and 3); mitogen-activated protein kinase (MAPK) phosphorylates Ser-62, Ser-67, and Ser-549

*Corresponding author. FAX: +81-564-52-7913

E-mail: yamagata@nips.ac.jp (sites 4, 5 and 6); and cyclin-dependent protein kinases (cdks) phosphorylate Ser-549 and Ser-551 (sites 6 and 7) $(1-5)$. Dephosphorylation of synapsin I was also studied recently; phospho-sites 1, 2, and 3 were shown to be preferentially dephosphorylated by protein phosphatase (PrP) 2A, and phospho-sites 4/5 and 6 were dephosphorylated by PrP2B (calcineurin, $\mathrm{Ca}^{2+} /$ calmodulin-dependent protein phosphatase) (6). Synapsins II and III, other structurally-related, different gene products of the synapsin family, have homologous N-terminal portions (domains $\mathrm{A}, \mathrm{B}$, and $\mathrm{C}$ ). Phospho-site 1 is conserved among all synapsins, but other sites are unique to synapsin I $(7-9)$.

In vitro studies using purified synapsin I showed that the dephospho-form of synapsin I binds synaptic vesicles, binds and bundles F-actin, and promotes Gactin polymerization. These functions are modified by phosphorylation of synapsin I as summarized in Fig. 2 


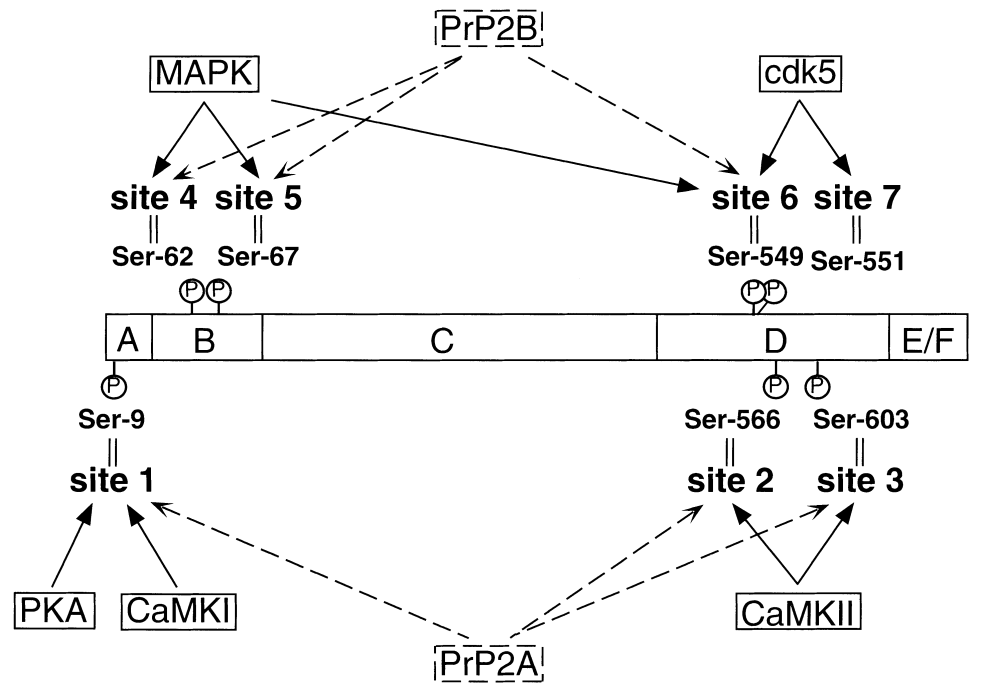

Fig. 1. Phosphorylation sites of synapsin I by various protein kinases. The domain structure of synapsin I (A through F) is schematically shown. The numbering of amino acids is based on the rat synapsin I sequence. Most effective protein phosphatases for dephosphorylation at each site are also shown. PKA, cyclic AMPdependent protein kinase; CaMKI, $\mathrm{Ca}^{2+} /$ calmodulindependent protein kinase I; CaMKII, $\mathrm{Ca}^{2+} /$ calmodulindependent protein kinase II; MAPK, mitogen-activated protein kinase; cdk5, cyclin-dependent protein kinase 5; PrP2A, protein phosphatase 2A; PrP2B, protein phosphatase 2B (calcineurin, $\mathrm{Ca}^{2+} / \mathrm{calmodulin}^{-}$dependent protein phosphatase).

synapsin I phosphorylated by

dephospho-synapsin I function

(1) G-actin nucleating activity (promoting G-actin polymerization)

(2) bundling actin filaments

(3) binding to synaptic vesicles

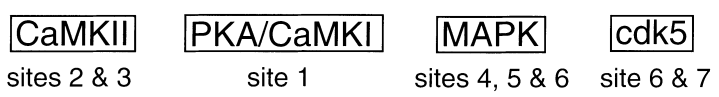

$\downarrow$

$\downarrow$

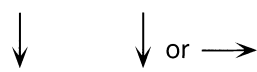

$\downarrow \downarrow$
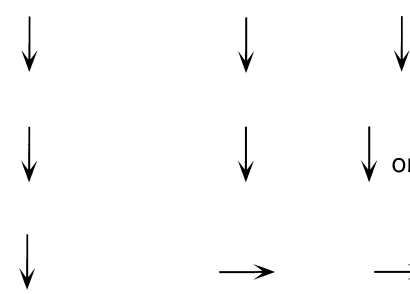

\section{facilitatory role in neurotransmitter release}

n.d.

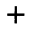

n.d.

Fig. 2. Summary of the effects of phosphorylation on synapsin I function. n.d., not determined.

$(3,4,10-15)$. Phosphorylation of synapsin I at either site generally reduces G-actin nucleating activity and F-actin-bundling activity, which seems to be related to the flexibility of the presynaptic actin network organization. Phosphorylation of synapsin I at sites 2 and 3 and at site 1 reduces its binding to synaptic vesicles, which seems to be related to synaptic vesicle mobilization for neurotransmitter release in the presynaptic terminal. Experiments using synaptosomes indicated the importance of CaMKII-dependent phosphorylation and MAPKdependent phosphorylation of synapsin I for the regulation of neurotransmitter release $(2,16,17)$.

Regulation of synapsin I phosphorylation by protein kinases and phosphatases has been studied by using in vitro preparations such as synaptosomes, brain slices, and cultured cells; and phospho-sites 2 and 3 were shown to be controlled by CaMKII and phospho-sites 4 and 5 , by MAPK and calcineurin in these preparations $(3,6,17-19)$. On the other hand, studies on the regulation of synapsin I phosphorylation in vivo in whole animals are still limited $(20-22)$.

In this minireview, I describe the in vivo regulation of synapsin I phosphorylation based on the study of an animal model of acute, reversible neuronal excitation induced by electroconvulsive treatment (ECT) in rats $(21,22)$. Some of the results are parallel to the ones obtained with in vitro preparations, but not others. I would like to emphasize the importance of the analyses of whole animals, which would become more informative when combined with the characterization of geneti- 

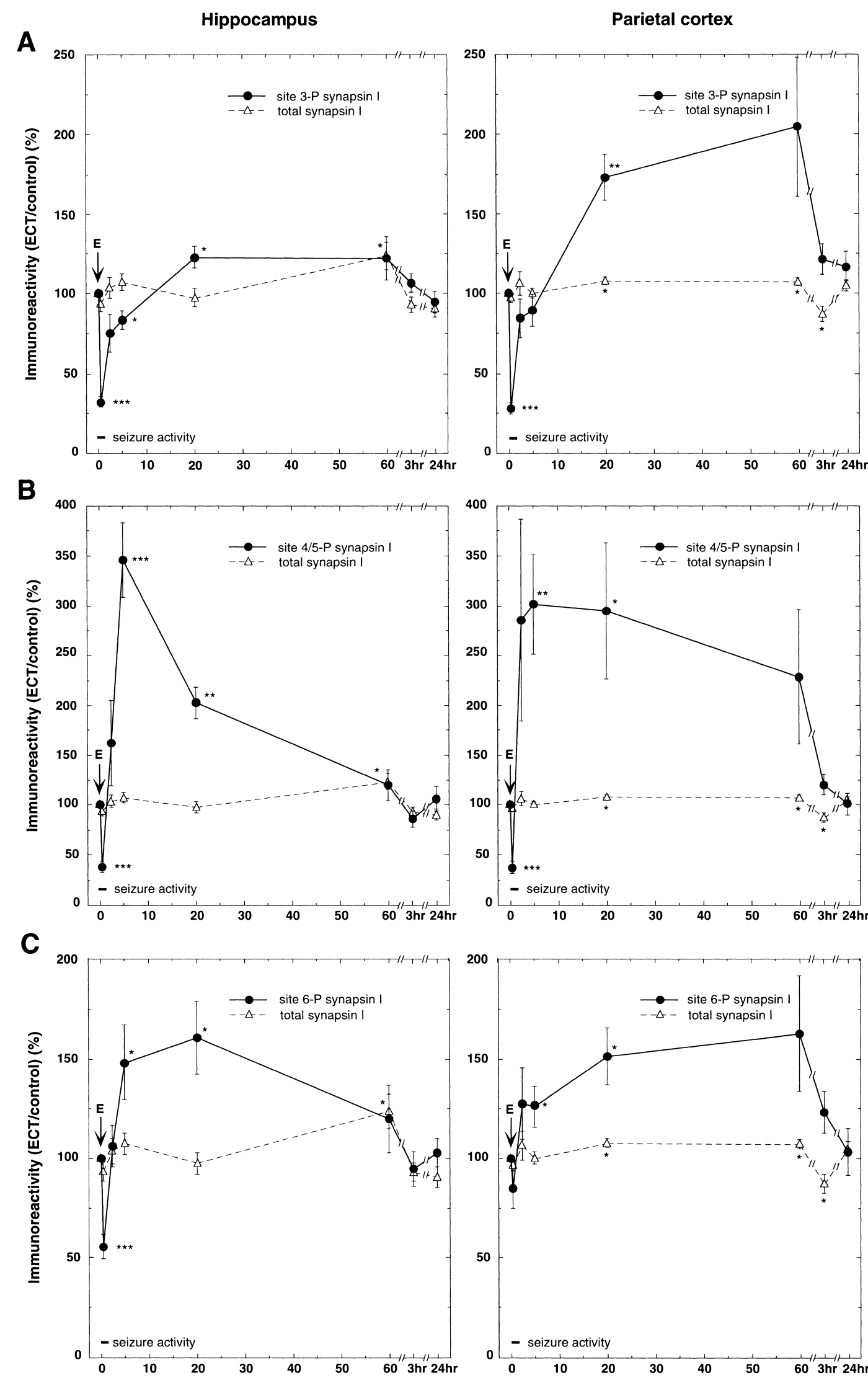

Fig. 3. Time after stimulation (minutes)

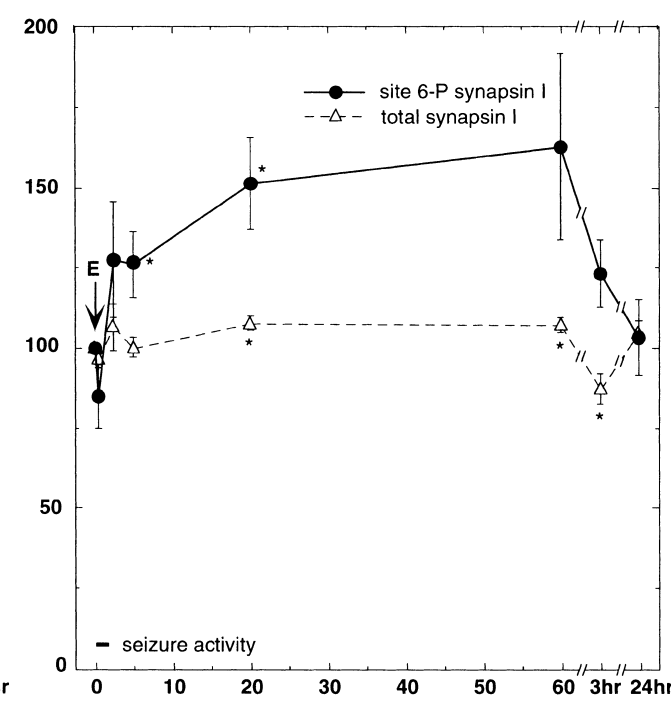

Time after stimulation (minutes) 
cally engineered animals, in understanding the physiological importance of synapsin I function in vivo.

\section{Changes in synapsin I phosphorylation after ECT}

ECT stimulation delivered through ear clips $(60 \mathrm{~Hz}$, sine wave, 100 volts, $2 \mathrm{~s}$ ) induced maximal seizure activity, starting with tonic convulsion succeeded by clonic convulsion, and the generalized seizure activity ceased in $90 \mathrm{~s}$ at the latest $(21,22)$. The induced seizure was completely reversible (23). In appropriate periods of time after the electrical stimulation, hippocampal and parieto-cortical homogenates were prepared and subjected to quantitative immunoblot analyses and protein kinase assays $(21,22)$. Among the time points examined, the earliest point ( $30 \mathrm{~s}$ after ECT) was during generalized seizure activity and other time points were all in the post-seizure period.

Phospho-synapsin I levels in ECT-animals were determined by using phospho-site specific antibodies (Fig. 3) (22). The levels of phospho-sites $3,4 / 5$, and 6 were all decreased during seizure activity in both the hippocampus and parietal cortex. The extent of the decrease in phospho-sites 3 and 4/5 was larger than that in phospho-site 6. Phospho-site 1 also showed an initial decrease during seizure activity (data not shown). Phospho-site $4 / 5$ showed a subsequent rapid large increase peaking at $5 \mathrm{~min}$ (Fig. 3B). Phospho-site 6 showed a slower moderate increase peaking at $20 \mathrm{~min}$ (Fig. 3C). Recovery of phospho-site 3 was much slower and a moderate increase was observed at later time points (Fig. 3A). All these changes were reversible and no longer significant at $60 \mathrm{~min}$, although the levels tended to be higher in the parietal cortex. The total synapsin I level remained relatively unchanged.

\section{Changes in protein kinase activities after ECT}

The $\mathrm{Ca}^{2+} /$ calmodulin-independent autonomous activity of CaMKII was decreased during seizure activity and then showed a small increase in parietal cortex at later time points (Fig. 4) (21). The change in autophosphorylation of CaMKII at Thr-286 $(\alpha) / 287(\beta)$, which is essential for autonomous activity, paralleled that in autonomous activity (data not shown) (21). The pattern of changes over time in the phospho-site 3 was similar to that of CaMKII activity, and the extent of the increase or decrease was larger in the phospho-site 3 than in CaMKII activity. MAPK activity showed a large increase during and soon after ECT without any initial decrease, peaked at $2.5 \mathrm{~min}$, and returned to the control level in 20 min (data not shown) (22). Cdk5 activity remained relatively unchanged (data not shown) (22).

\section{Effect of SL327, a MEK inhibitor, on the increase in synapsin I phosphorylation}

When rats were pretreated with SL327, a MAPK kinase (MEK) inhibitor that crosses the blood-brainbarrier $(24,25)$ prior to ECT, significant suppression was observed not only in the increase in MAPK activity, but also in that in phospho-site $4 / 5$ level (Fig. 5) (22). Thus, the increase in phospho-site 4/5 level after ECT was attributable to increased MAPK activity induced by ECT.

\section{Regulation of synapsin I phosphorylation by protein kinases and phosphatases in rats in vivo}

In vitro studies showed that the phospho-site 3 of synapsin I was a good substrate for PrP2A (6), and autophosphorylated CaMKII was dephosphorylated by PrPs 1, 2A, and 2C and CaMKII phosphatase (26-31). Both of them are poor substrates for calcineurin $(6,32$, 33). Since both the level of the phospho-site 3 and the autonomous activity of CaMKII were decreased during seizure activity induced by ECT, it is most probable that the activation of PrP2A should be responsible for their dephosphorylation. The fact that the level of the phospho-site 1, another good substrate for PrP2A, was similarly decreased during seizure activity also supports this assumption. The mechanism of PrP2A activation during seizure activity is not clear at this moment.

On the other hand, a decrease in phospho-sites 4/5 and 6 during seizure activity seems to be caused by the activation of calcineurin, because these sites were shown to be good substrates for calcineurin in vitro, and high $\mathrm{K}^{+}$-depolarization of synaptosomes in the presence

Fig. 3. Changes in the levels of phosphorylation of synapsin I at sites 3 (A), 4/5 (B), and 6 (C) after ECT in homogenates from the hippocampus and parietal cortex. Phospho-synapsin I levels at each site and total synapsin I level were determined by quantitative immunoblot analyses using phospho-site specific and anti-synapsin I antibodies, respectively. The ordinate expresses the values obtained from ECT animals as percent of controls. The abscissa expresses the time after the electrical stimulation. An arrow with "E" at time zero indicates ECT stimulation and a horizontal bar in the left lower corner indicates the approximate duration of seizure activity. Data are shown as means \pm S.E.M. (bars) $(\mathrm{n}=5-10)$ except for that at time 0 , which indicates the control value $(100 \%)$. Significantly different values from the control $(100 \%)$ are indicated: ${ }^{*} P<0.1,{ }^{* *} P<0.01,{ }^{* * *} P<0.001$ (Bonferroni-Holm test). Modified from Yamagata et al. (Ref. 22). 
Hippocampus

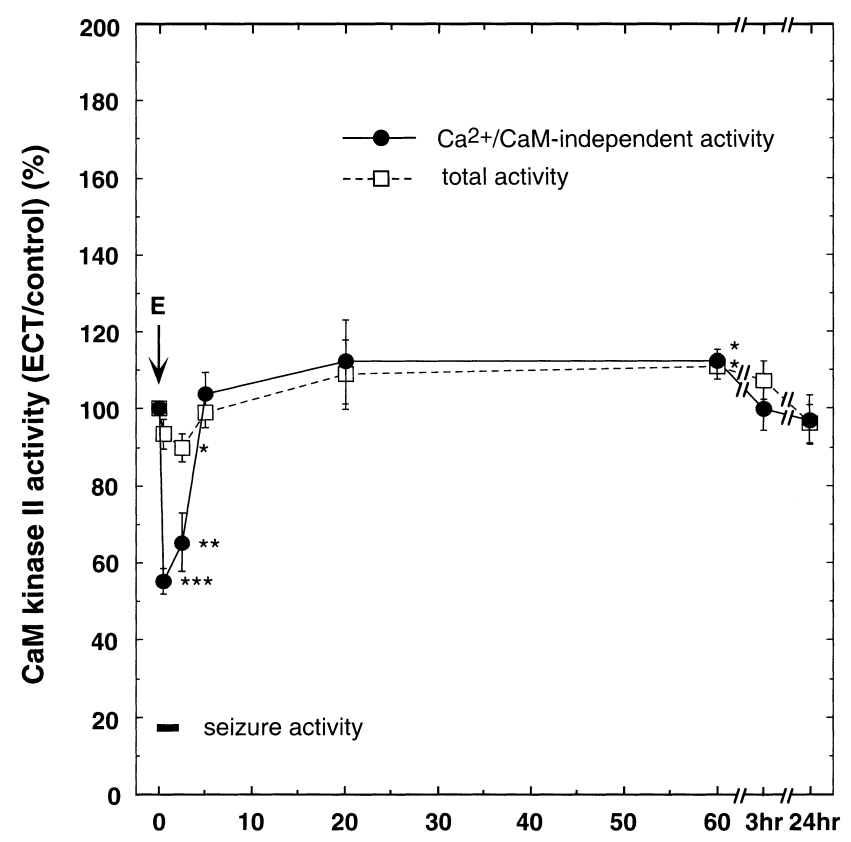

Time after stimulation (minutes)
Parietal cortex

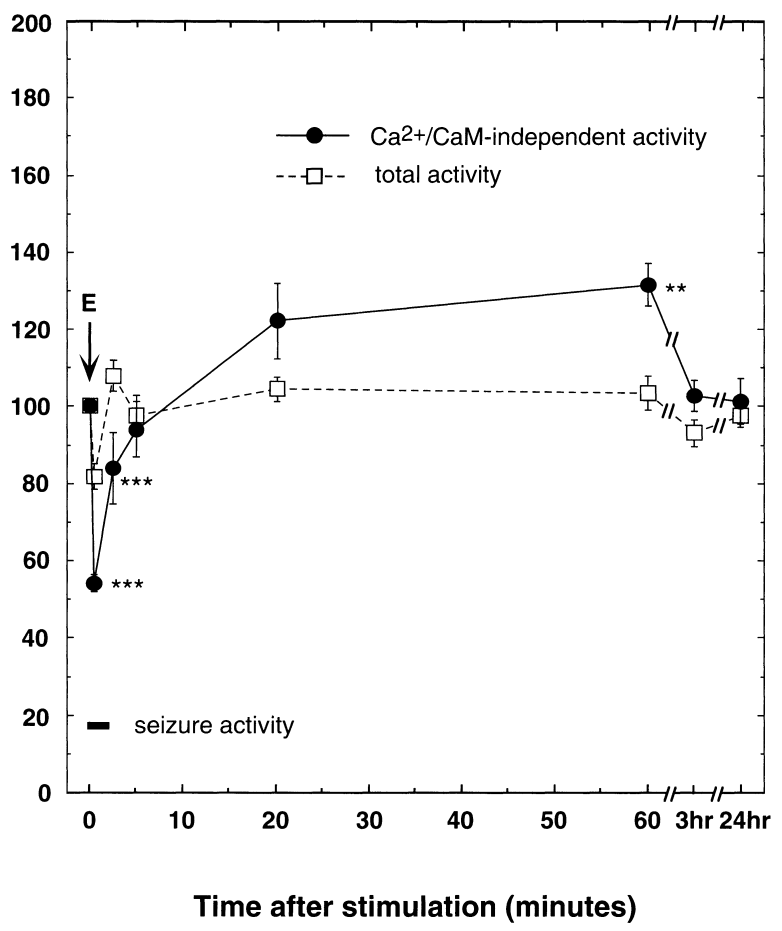

Fig. 4. Changes in the $\mathrm{Ca}^{2+} /$ calmodulin-independent autonomous activity and the total activity of CaMKII after ECT in homogenates from the hippocampus and parietal cortex. Activities were measured by using a specific peptide substrate. Other details are as in the legend of Fig. 3. Modified from Yamagata and Obata (Ref. 21).

of extracellular $\mathrm{Ca}^{2+}$ also induced a decrease in phosphorylation at these sites (6). Other proteins such as highmolecular-weight MAPs (MAP2a and MAP2b) were also reported to be dephosphorylated soon after ECT (34). Such dephosphorylation of a variety of proteins may be a common phenomenon induced by seizure activity. In fact, in another study, an even larger decrease was observed in phospho-sites $1,3,4 / 5$, and 6 in the status epilepticus induced by kainic acid in rats (35). The initial decrease in phospho-site $4 / 5$ after ECT was soon overcome by a subsequent large increase, which was attributable to MAPK activation. The more delayed smaller increase in phospho-site 6 was not shown to be attributable to MAPK activation, and another unknown protein kinase may be involved.

\section{Physiological implication of dynamic changes in synapsin I phosphorylation by ECT in vivo}

ECT is an effective treatment for many psychiatric diseases such as major depression and schizophrenia in humans, especially in pharmacotherapy-resistant cases, but its mode of action still remains unknown (36). Studies of animal models have shown increased neurogenesis, mossy fiber sprouting, and an enhanced synap- tic response following repeated ECT (37 - 40). Dynamic changes in synapsin I phosphorylation induced by ECT may be involved in such plastic changes in the presynaptic terminal (Fig. 6). The initial rapid dephosphorylation at all sites of synapsin I implies a more rigid organization of actin-cytoskeleton and sequestration of remaining synaptic vesicles to reserve pool during seizure activity. The former may be important for preserving the presynaptic morphological structure from epileptic discharges, and the latter may be beneficial to prevent further neurotransmitter release, because massive release should have already occurred by electrical stimulation itself. The following increase in phosphorylation largely at site $4 / 5$ after termination of the seizure activity may lead to loosening of the presynaptic actinnetwork organization and enhanced availability of synaptic vesicles for release, which may be related to possible plastic changes such as synaptic reorganization and enhanced synaptic response observed after repeated ECT. More studies on the regulation of synapsin I phosphorylation in vivo will shed light on the normal physiology and pathophysiology of neuronal excitation, as well as on the therapeutic mechanisms of ECT in humans. 
Hippocampus

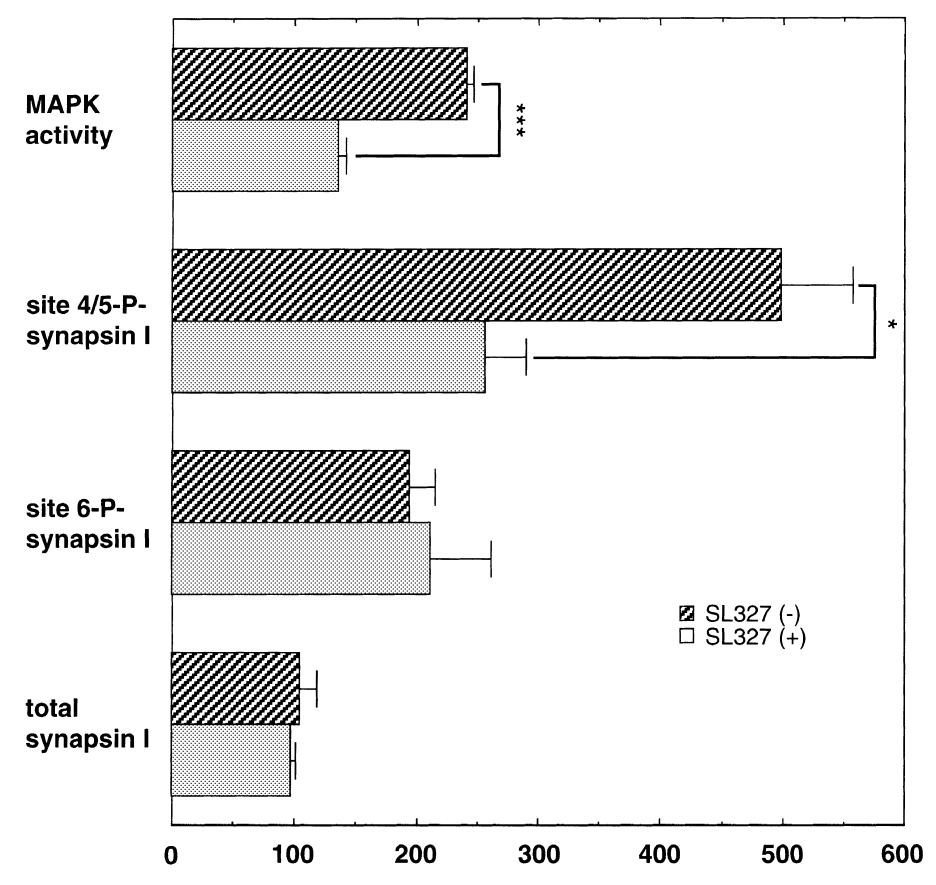

Parietal cortex

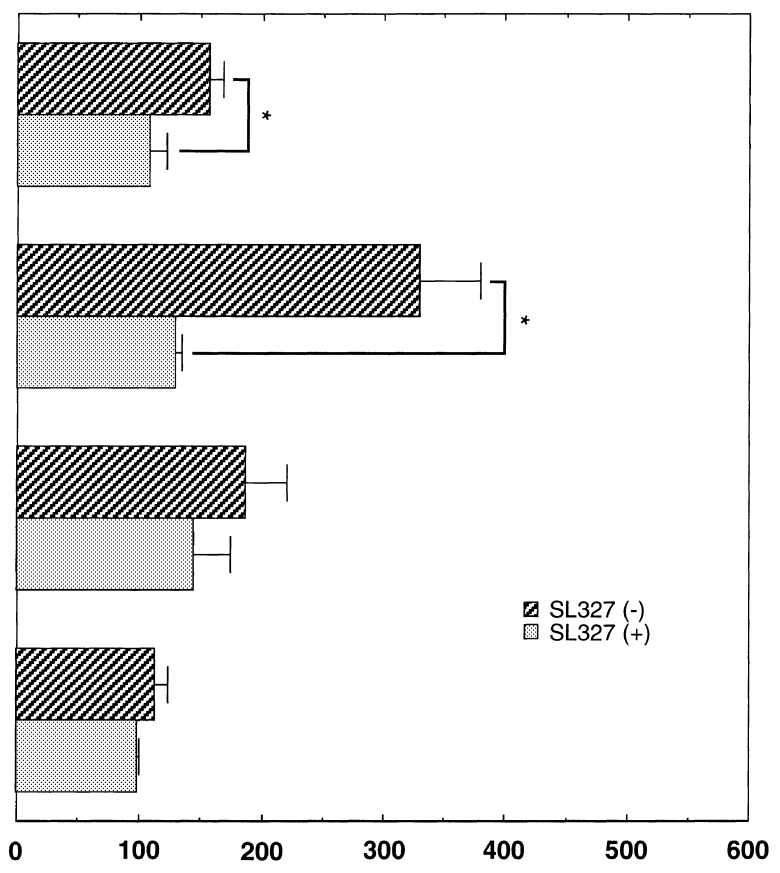

Kinase activity or immunoreactivity (ECT $5^{\prime} /$ control) (\%)

Fig. 5. Effects of SL327 on the increase in MAPK activity and the phospho-synapsin I levels after ECT. ECT samples were obtained at $5 \mathrm{~min}$ after ECT and the values are expressed as percent of controls. Vehicle-treated and SL327-treated groups are compared. Data are shown as means \pm S.E.M. (bars) $(n=3)$. Significantly lower values in SL327-treated samples than those in vehicle-treated samples are indicated: ${ }^{*} P<0.05,{ }^{* * *} P<0.001$ (one-tailed paired $t$-test). Modified from Yamagata et al. (Ref. 22).

\section{During seizure activity}

\begin{tabular}{|l|}
\hline Rapid dephosphorylation \\
at all sites of synapsin I
\end{tabular}

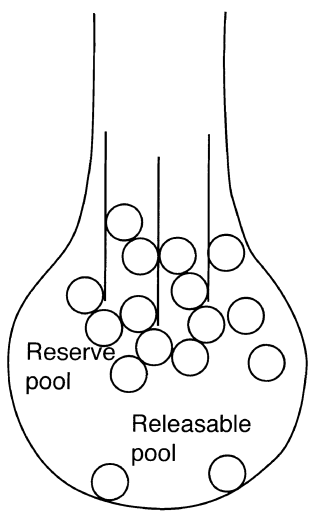

More rigid presynaptic actin-network organization

Sequestration of synaptic vesicles to reserve pool

\section{Post-seizure period}

Increased phosphorylation at site $4 / 5$ of synapsin I

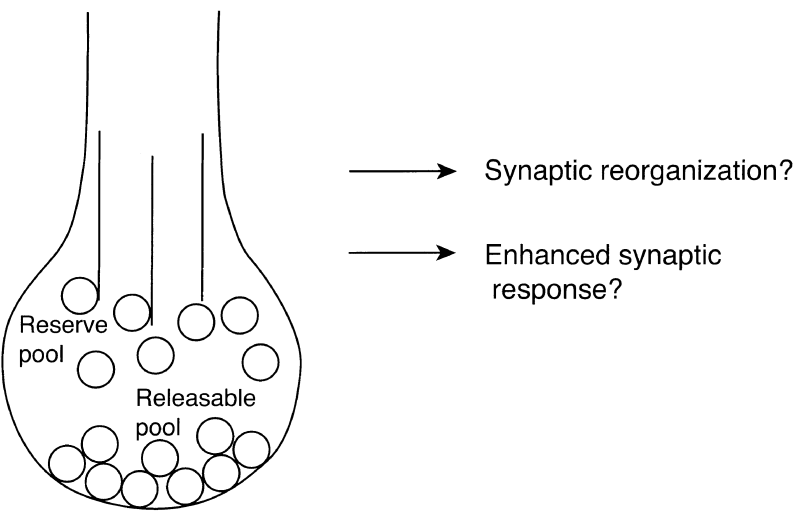

Loosening of presynaptic actin-network organization Enhanced availability of synaptic vesicles for release

Fig. 6. Schematic illustration of changes in synapsin I phosphorylation induced by ECT and its physiological implications. 


\section{Acknowledgments}

Phospho-synapsin I antibodies were provided by Drs. A.J. Czernik and P. Greengard, Rockefeller Univ., and SL327 was provided by Dr. J.M. Trzaskos, DuPont Pharm. Co. This study was supported by grants-in-aid for scientific research from the Ministry of Education, Culture, Sports, Science and Technology of Japan (07808095 and 10680756).

\section{References}

1 De Camilli P, Benfenati F, Valtorta F, Greengard P. The synapsins. Annu Rev Cell Biol. 1990;6:433-460.

2 Greengard P, Valtorta F, Czernik AJ, Benfenati F. Synaptic vesicle phosphoproteins and regulation of synaptic function. Science. 1993;259:780-785.

3 Jovanovic JN, Benfenati F, Siow YL, et al. Neurotrophins stimulate phosphorylation of synapsin I by MAP kinase and regulate synapsin I-actin interactions. Proc Natl Acad Sci USA. 1996;93:3679-3683.

4 Matsubara M, Kusubata M, Ishiguro K, Uchida T, Titani K, Taniguchi H. Site-specific phosphorylation of synapsin I by mitogen-activated protein kinase and cdk5 and its effects on physiological functions. J Biol Chem. 1996;271:21108-21113.

5 Hilfiker S, Pieribone VA, Czernik AJ, Kao H-T, Augustine GJ, Greengard P. Synapsins as regulators of neurotransmitter release. Philos Trans R Soc Lond B Biol Sci. 1999;354:269-279.

6 Jovanovic JN, Sihra TS, Nairn AC, Hemmings HC Jr, Greengard $\mathrm{P}$, Czernik AJ. Opposing changes in phosphorylation of specific sites in synapsin I during $\mathrm{Ca}^{2+}$-dependent glutamate release in isolated nerve terminals. J Neurosci. 2001;21:7944-7953.

7 Südhof TC, Czernik AJ, Kao H-T, et al. Synapsins: mosaics of shared and individual domains in a family of synaptic vesicle phosphoproteins. Science. 1989;245:1474-1480.

8 Hosaka M, Südhof TC. Synapsin III, a novel synapsin with an unusual regulation by $\mathrm{Ca}^{2+}$. J Biol Chem. 1998;273:1337113374.

9 Kao H-T, Porton B, Czernik AJ, et al. A third member of the synapsin gene family. Proc Natl Acad Sci USA. 1998;95:46674672.

10 Schiebler W, Jahn R, Doucet J-P, Rothlein J, Greengard P. Characterization of synapsin I binding to small synaptic vesicles. J Biol Chem. 1986;261:8383-8390.

11 Bähler M, Greengard P. Synapsin I bundles F-actin in a phosphorylation-dependent manner. Nature. 1987;326:704-707.

12 Petrucci TC, Morrow JS. Synapsin I: an actin-bundling protein under phosphorylation control. J Cell Biol. 1987;105:13551363.

13 Valtorta F, Greengard P, Fesce R, Chieregatti E, Benfenati F. Effects of the neuronal phosphoprotein synapsin I on actin polymerization. I. Evidence for a phosphorylation-dependent nucleating effect. J Biol Chem. 1992;267:11281-11288.

14 Hosaka M, Hammer RE, Südhof TC. A phospho-switch controls the dynamic association of synapsins with synaptic vesicles. Neuron. 1999;24:377-387.

15 Chi P, Tsou K, Greengard P, Ryan TA. Synapsin dispersion and reclustering during synaptic activity. Nature Neurosci.
2001;4:1187-1193.

16 Nichols RA, Sihra TS, Czernik AJ, Nairn AC, Greengard P. Calcium/calmodulin-dependent protein kinase II increases glutamate and noradrenaline release from synaptosomes. Nature. 1990;343:647-651.

17 Jovanovic JN, Czernik AJ, Fienberg AA, Greengard P, Sihra TS. Synapsins as mediators of BDNF-enhanced neurotransmitter release. Nature Neurosci. 2000;3:323-329.

18 Gorelick FS, Wang JKT, Lai Y, Nairn AC, Greengard P. Autophosphorylation and activation of $\mathrm{Ca}^{2+} /$ calmodulin-dependent protein kinase II in intact nerve terminals. J Biol Chem. 1988; 263:17209-17212.

19 Sihra TS, Wang JKT, Gorelick FS, Greengard P. Translocation of synapsin I in response to depolarization of isolated nerve terminals. Proc Natl Acad Sci USA. 1989;86:8108-8112.

20 Yamagata Y, Obata K, Greengard P, Czernik AJ. Increase in synapsin I phosphorylation implicates a presynaptic component in septal kindling. Neuroscience. 1995;64:1-4.

21 Yamagata Y, Obata K. Dynamic regulation of the activated, autophosphorylated state of $\mathrm{Ca}^{2+} /$ calmodulin-dependent protein kinase II by acute neuronal excitation in vivo. J Neurochem. 1998;71:427-439.

22 Yamagata Y, Jovanovic JN, Czernik AJ, Greengard P, Obata K. Bidirectional changes in synapsin I phosphorylation at MAP kinase-dependent sites by acute neuronal excitation in vivo. $\mathrm{J}$ Neurochem. 2002;80:835-842.

23 Swinyard EA. Electrically induced convulsions. In: Purpura DP, Penry JK, Tower DB, Woodbury DM, Walter RD, editors. Experimental models of epilepsy - a manual for the laboratory worker. New York: Raven Press; 1972. p. 433-458.

24 Atkins CM, Selcher JC, Petraitis JJ, Trzaskos JM, Sweatt JD. The MAPK cascade is required for mammalian associative learning. Nature Neurosci. 1998;1:602-609.

25 Selcher JC, Atkins CM, Trzaskos JM, Paylor R, Sweatt JD. A necessity for MAP kinase activation in mammalian spatial learning. Learning Memory. 1999;6:478-490.

26 Schworer CM, Colbran RJ, Soderling TR. Reversible generation of a $\mathrm{Ca}^{2+}$-independent form of $\mathrm{Ca}^{2+}$ (calmodulin)-dependent protein kinase II by an autophosphorylation mechanism. J Biol Chem. 1986;261:8581-8584.

27 Lai Y, Nairn AC, Greengard P. Autophosphorylation reversibly regulates the $\mathrm{Ca}^{2+} /$ calmodulin-dependence of $\mathrm{Ca}^{2+} /$ calmodulindependent protein kinase II. Proc Natl Acad Sci USA. 1986;83: 4253-4257.

28 Miller SG, Patton BL, Kennedy MB. Sequences of autophosphorylation sites in neuronal type II CaM kinase that control $\mathrm{Ca}^{2+}$-independent activity. Neuron. 1988;1:593-604.

29 Lou LL, Schulman H. Distinct autophosphorylation sites sequentially produce autonomy and inhibition of the multifunctional $\mathrm{Ca}^{2+} /$ calmodulin-dependent protein kinase. J Neurosci. 1989;9:2020-2032.

30 Fukunaga K, Kobayashi T, Tamura S, Miyamoto E. Dephosphorylation of autophosphorylated $\mathrm{Ca}^{2+} /$ calmodulin-dependent protein kinase II by protein phosphatase 2C. J Biol Chem. 1993;268:133-137.

31 Ishida A, Kameshita I, Fujisawa H. A novel protein phosphatase that dephosphorylates and regulates $\mathrm{Ca}^{2+} /$ calmodulin-dependent protein kinase II. J Biol Chem. 1998;273:1904-1910.

32 Goto S, Yamamoto H, Fukunaga K, Iwasa T, Matsukado Y, Miyamoto E. Dephosphorylation of microtubule-associated 
protein $2, \tau$ factor, and tubulin by calcineurin. J Neurochem. $1985 ; 45: 276-283$

33 King MM, Huang CY, Chock PB, et al. Mammalian brain phosphoproteins as substrates for calcineurin. J Biol Chem. 1984;259:8080-8083.

34 Bhat RV, Engber TM, Finn JP, et al. Region-specific targets of p42/p44MAPK signaling in rat brain. J Neurochem. 1998;70: 558-571.

35 Yamagata Y, Obata K. Regulation of synapsin I phosphorylation in prolonged seizure activity in rat brain in vivo. Neurosci Res. 2002;Suppl 26:S24.

36 Fink M. Convulsive therapy: a review of the first 55 years. J Affect Disord. 2001;63:1-15.
37 Vaidya VA, Siuciak JA, Du F, Duman RS. Hippocampal mossy fiber sprouting induced by chronic electroconvulsive seizures. Neuroscience. 1999;89:157-166.

38 Gombos Z, Spiller A, Cottrell GA, Racine RJ, Burnham WM. Mossy fiber sprouting induced by repeated electroconvulsive shock seizures. Brain Res. 1999;844:28-33.

39 Stewart C, Jeffery K, Reid I. LTP-like synaptic efficacy changes following electroconvulsive stimulation. Neuroreport. 1994;5: 1041-1044.

40 Burnham WM, Cottrell GA, Diosy D, Racine RJ. Long-term changes in entorhinal-dentate evoked potentials induced by electroconvulsive shock seizures in rats. Brain Res. 1995;698: 180-184. 